УДК 574+504.54:581.524

\author{
Н. Н. Назаренко ${ }^{1}$ О. А. Дидур ${ }^{2}$
}

${ }^{1}$ Наичональный университет биоресурсов и природопользования Украинь, г. Киев

${ }^{2}$ Днепропетровский национальный университет им. Олеся Гончара

\title{
ЦЕНОМОРФЫ ЕСТЕСТВЕННЫХ ЛИСТВЕННЫХ ЛЕСОВ СЕВЕРНОЙ СТЕПИ УКРАИНЫ
}

\begin{abstract}
Экспертно-статистическими методами проведен анализ ценоморф 156 видов сосудистых растений естественных лесов северной Степи Украины. Обосновано включение вида в определенную ценоморфу, определены ряды замещения ценоморф и факторы формирования ценоморфических групI. Статистическими методами доказана возможность использования ценоморф не только для идентификации ценотических особенностей сообществ, но и фитоиндикации режимов абиотических факторов. Выделение переходных ценоморф не всегда целесообразно, зависит от типа экосистемы, в которой выполняется ценоморфический анализ.
\end{abstract}

$$
\begin{gathered}
\text { Н. М. Назаренко }{ }^{1} \text {, О. О. Дідур }{ }^{2} \\
{ }^{1} \text { Національний університет біоресурсів і природокористування Украйни, м. Київ } \\
{ }^{2} \text { Дніпропетровський нащіональний університет ім. Олеся Гончара }
\end{gathered}
$$

\section{ЦЕНОМОРФИ ПРИРОДНИХ ЛИСТЯНИХ ЛІСІВ ПІВНІЧНОГО СТЕПУ УКРАЇНИ}

Експертно-статистичними методами проведено аналіз ценоморф 156 видів судинних рослин природних листяних лісів північного Степу України. Обгрунтовано віднесення виду до певної ценоморфи, виділено ряди заміщення ценоморф і фактори формування ценоморфічних груп. Статистичними методами доведено можливість використання ценоморф не тільки для ідентифікації ценотичних особливостей угруповань, а і фітоіндикації режимів абіотичних факторів. Визначення перехідних ценоморф не завжди доцільне, залежить від типу екосистеми, для якої виконується ценоморфічний аналіз.

\author{
N. N. Nazarenko ${ }^{1}$, O. O. Didur ${ }^{2}$ \\ ${ }^{l}$ National University of Life and Environmental Science of Ukraine, Kyiv \\ ${ }^{2}$ Oles' Honchar Dnipropetrovsk National University
}

\section{COENOMORPHS OF NATURAL DECIDUOUS FORESTS IN NORTHERN STEPPE OF UKRAINE}

Coenomorphs of 156 vascular plant species of natural deciduous forests in Northern Steppe of Ukraine has been analyzed by the expert and statistical analysis. The inclusion of the species in the particular coenomorph has been proved. Series of the coenomorphs replacement and factors of coenomorph groups forming have been determined. Coenomorphs may be used as a phytometer of coenotical and abiotic conditions. The determination of transitional coenomorphs is not always expedient and depends on the type of ecosystem, which is analyzed.

(C) Н. Н. Назаренко, О. А. Дидур, 2012 


\section{Введение}

Различные функциональные (в широком понимании) группы растений широко используются в геоботанических и экологических исследованиях для решения задач, которые требуют оценки или анализа структурно-функциональных особенностей растительного покрова. Одним из таких подходов является анализ эколого-ценотических групп (ЭЦГ) растений [4]. Данная система широко используется в лесной экологии для оценки биотического, экосистемного и структурного разнообразия растительного покрова, сукцессионного статуса экосистем, моделирования и прогнозирования динамики растительных сообществ лесной зоны Европейской России. Однако сами эксперты полагают, что для южных лесных территорий необходимо расширение числа ЭЦГ и дальнейшая их детализация [8]. Альтернативой системе ЭЦГ является менее распространенная система ценоморф, предложенная и разработанная А. Л. Бельгардом для анализа экосистем степной зоны [2]. Ценоморфы автором понимаются как «...приспособления видов к фитоценозу в целом... . Среди ценоморф можно различать сильванты (лесные виды), степанты (степные виды), пратанты (луговые виды), палюданты (болотные виды), галофиты (виды, связанные с засоленными почвами) и рудеранты (сорные виды)...».

Принципиальная схема ценоморф разработана А. Л. Бельгардом [2], но также необходимо отметить более поздние сводки ценоморф и экоморфического анализа в целом [3; 6; 9]. Ценоморфический анализ лесных ценозов по Бельгарду выполняется в рамках экоморфического анализа экосистем на основе сравнения долей ценоморф, входящих в состав растительных сообществ, с учетом количественных характеристик видов. Сами виды относятся к той или иной ценоморфе на основе анализа их встречаемости в различных типах сообществ. Таким образом, во всех случаях ценоморфы определяются экспертно. При этом следует отметить невозможность однозначного определения ценоморфы для многих видов, вследствие их широкой встречаемости в экосистемах различного типа, например, для опушечно-полянного комплекса лесных видов. Также отнесение вида к той или иной ценоморфе в некоторой степени является условным, поскольку резкого разграничения между близкими ценоморфами не наблюдается. Особенно сложным является ценоморфический анализ амфиценотических (по Бельгарду [1]) экосистем, для которых характерно одновременное наличие видов полярных ценоморф. Оценка ценоморф таких экосистем выполнена автором на примере интразональных лесных экосистем террас малых рек северной Степи Украины [7].

Цель данной работы - уточнить систему ценоморф естественных лесов северной Степи Украины, включая байрачные, пристенные и краткопоемные дубравы, и интразональные лесные экосистемы террас малых рек.

\section{Материал и методы исследований}

Исследования проводились на территории Днепропетровской и северной части Запорожской области, где зональным типом растительности являются степные фитоценозы, а по террасам малых рек сформированы типичные естественные северостепные лиственные леса. Анализ выполнялся на основе экспертно-статистической схемы, предложенной для анализа ЭЦГ видов сосудистых растений Лесной зоны Европейской России [8], которая включала в себя

1) экспертное определение ценоморфы;

2) расчет ценотических координат видов на основе их ординации методом неметрического многомерного шкалирования (NMS) [12; 13] с использованием коэффициента Серенсена - Чекановского (Брея - Кертиса); 
3) определение центроидов видов в экологическом факторном пространстве фитоиндикационных шкал;

4) многомерный дискриминантный анализ (ДА) видов в экологическом и эколого-ценотическом пространствах [12; 13].

Фитоиндикационные шкалы $[5 ; 11]$ выбраны по следующим факторам: термоклимат $(\mathrm{Tm})$, континентальность $(\mathrm{Kn})$, омбро- $(\mathrm{Om})$ и криоклимат $(\mathrm{Cr})$, освещенность $(\mathrm{Lc})$, почвенное увлажнение $(\mathrm{Hd})$, солевой $(\mathrm{Tr})$, кислотный $(\mathrm{Rc})$, азотный $(\mathrm{Nt})$ режимы и режим содержания гумуса (Hm). Все расчеты выполнены в пакетах PC-ORD 5.0 и Statistica 6.0.

\section{Результаты и их обсуждение}

Для исследованных лесов экспертным способом 156 видов флоры из описаний отнесены к 33 ценоморфам. Согласно ограничениям дискриминантного анализа, ценоморфы, представленные одним видом, объединялись с близкими им ценоморфами. В анализе представлены следующие группы (индексация ценоморф дана по В. В. Тарасову [9]): 1) луговые галофиты (PrHal); 2) болотная (Pal); 3) болотно-луговая (PalPr); 4) болотно-лесная (PalSil, SilPal); 5) лугово-болотная (PrPal); 6) луговая (Pr); 7) луговые псаммофиты (PrPs); 8) лугово-сорная (PrRu); 9) лугово-лесная (PrSil); 10) псаммофиты и псаммофитно-сорная (Ps, PsRu); 11) лесно-псаммофитная (PsSil, SilPs); 12) степопсаммофитная (PsSt, StPs); 13) сорная (Ru); 14) сорно-степная (RuSt); 15) сорно-луговая $(\mathrm{RuPr})$; 16) сорно-лесная (RuSil); 17) лесная (Sil); 18) лесо-луговая (SilPr); 19) лесосорная (SilRu); 20) лесо-степная (SilSt); 21) степная (St); 22) лугово-степная (PrSt, StPr); 23) степо-сорная (StRu); 24) степо-лесная (StSil).

После статистической проверки методами дискриминантного анализа правильно экспертно классифицированными оказалось 93 вида (60 \%) (табл. 1), для остальных видов ценоморфа была изменена. Из числа исследованных видов 77 (49 \%) по результатам анализа определяются как «ядерные» [8].

Абсолютно правильно (100 \%) экспертно отнесены виды к следующим ценоморфам: 1) луговые галофиты; 7) луговые псаммофиты; 10) псаммофиты и псаммофильные сорняки; 12) степные псаммофиты. Фактически это ценоморфы, приуроченные к специфическим псаммофильным экосистемам первой надпойменной речной террасы (арены). Устойчивыми группами оказались также: 17) сильвантная, 23) степорудеральная и 13) рудеральная. Для сильвантов и рудерантов отмечено возрастание числа видов в группе. Достаточно устойчивыми также были 15) сорно-луговая, 20) лесо-степная, 22) лугово-степная ценоморфы, приуроченные преимущественно к опушечно-полянным комплексам северо-степных лиственных лесов. Наличие семи ценоморф для исследованных лесов статистическими методами не подтвердилось.

Ценоспектр видов исследованных лесов (табл. 2) показал, что ведущую часть флоры (40 \%) формируют сильванты. Общая доля сильвантной компоненты (вместе с сорно- и степо-лесными видами) составляет 47 \%. Второе место по численности занимает рудеральная группа (13\%). Общая доля рудеральной компоненты (вместе с лесными и степными рудерантами) составляет $16 \%$. Такой ее сравнительно высокий процент связан с включением в анализ антропогенных и антропогенно трансформированных колков, формирующихся на участках оседания земной поверхности в результате шахтных подработок в Западном Донбассе и пионерных лесов на осолоделых почвах. Третья позиция по численности характерна для видов степных (12\%) и болотных $(11 \%)$ ценоморф. Анализ видов после статистической оценки показал, что чаще всего отмечены переходы видов в лесную (27 видов, 17 \%), рудеральную и лесо-степную (по 7 видов) ценоморфы. Несмотря на большое количество переходных групп, цено- 
морфы характеризуются достаточно высокой вариабельностью, а переход вида в ту или иную ценоморфу зависит от типа анализируемого растительного сообщества. Если в описаниях преобладают классические лесные экосистемы, то отмечается тяготение видов переходных ценоморф к сильвантной группе, при наличии рудеральных сообществ - к рудеральной и т. д.

Таблицุа 1

Характеристика ценоморф видов степных лиственных лесов

\begin{tabular}{|c|c|c|c|c|c|}
\hline № & Ценоморфа & $\begin{array}{l}\text { Экспертное } \\
\text { число видов }\end{array}$ & $\begin{array}{c}\text { Правильность } \\
\text { классификации, \% }\end{array}$ & $\begin{array}{c}\text { Число видов } \\
\text { после анализа }\end{array}$ & $\begin{array}{c}\text { Число } \\
\text { «ядерных» видов }\end{array}$ \\
\hline 1 & HalPr, PrHal & 2 & 100,0 & 2 & 2 \\
\hline 2 & Pal & 5 & 40,0 & 5 & 3 \\
\hline 3 & PalPr & 2 & 0,0 & - & - \\
\hline 4 & PalSil, SilPal & 5 & 60,0 & 4 & 3 \\
\hline 5 & PrPal & 7 & 57,1 & 8 & 2 \\
\hline 6 & $\operatorname{Pr}$ & 4 & 25,0 & 2 & 1 \\
\hline 7 & PrPs & 2 & 100,0 & 2 & \\
\hline 8 & $\operatorname{PrRu}$ & 3 & 0,0 & - & - \\
\hline 9 & PrSil & 3 & 0,0 & - & - \\
\hline 10 & Ps, PsRu & 2 & 100,0 & 2 & 2 \\
\hline 11 & PsSil, SilPs & 2 & 0,0 & - & - \\
\hline 12 & PsSt, StPs & 2 & 100,0 & 4 & 3 \\
\hline 13 & $\mathrm{Ru}$ & 18 & 72,2 & 20 & 7 \\
\hline 14 & RuSt & 3 & 0,0 & - & - \\
\hline 15 & $\mathrm{RuPr}$ & 3 & 66,7 & 4 & 2 \\
\hline 16 & RuSil & 9 & 55,6 & 8 & 1 \\
\hline 17 & Sil & 42 & 85,7 & 63 & 37 \\
\hline 18 & SilPr & 10 & 30,0 & 5 & 1 \\
\hline 19 & SilRu & 6 & 0,0 & 2 & - \\
\hline 20 & SilSt & 8 & 62,5 & 12 & 7 \\
\hline 21 & St & 2 & 0,0 & - & - \\
\hline 22 & PrSt, StPr & 8 & 62,5 & 7 & 1 \\
\hline 23 & StRu & 4 & 75,0 & 3 & 3 \\
\hline 24 & StSil & 4 & 50,0 & 3 & 2 \\
\hline & В целом & 156 & 59,6 & 156 & 77 \\
\hline
\end{tabular}

Анализ расположения видов в пространстве абиотических факторов (табл. 3) показал четкую их обособленность - разница определяется не только в пределах экологических свит, но и по типам режимов факторов (по Цыганову [11]). Наилучше обособленность ценоморф в экологическом пространстве отмечается по фактору почвенного увлажнения: очень сухие ультраксерофильные (0) - StRu; сухие ксерофильные (0-1) - PsSt, StPs, Ps, PrSt, StPr; суховатые мезо-ксерофильные (1) - Ru, SilSt, SilPr; свежеватые ксеромезофильные (1-2) - PrPs; свежие мезофильные (2) - RuSil, StSil, RuPr, Sil; влажноватые гигромезофильные (2-3) - Pr; влажные мезогигрофильные (3) - SilRu; сыроватые гигрофильные (3-4) - HalPr, PrHal; сырые гигрофильные (4) - PrPal; ультрагигрофильные мокроватые (4-5) - SilPal; ультрагигрофильные мокрые (5) - Pal.

По результатам ординации центроидов ценоморф в пространстве абиотических факторов выявлены следующие экологические их особенности.

1. Луговые галофиты характеризуются минимальными показателями терморежима, криорежима и освещенности (нелесная экологическая свита режима открытых пространств). В условиях степных лиственных лесов наличие этой ценоморфы не является индикатором засоления почв. 
2. Болотная ценоморфа характеризуются максимальным показателем режима почвенного увлажнения (мокро-лесолуговая свита) и режимом содержания гумуса. Также близким к максимальному показателю режима гумуса характеризуется и луговая ценоморфа.

Таблица 2

Ценоспектр степных лиственных лесов

\begin{tabular}{|c|l|c|c|}
\hline № & \multicolumn{1}{|c|}{ Ценоморфа } & Экспертная оценка, \% & После анализа, \% \\
\hline 1 & HalPr, PrHal & 1,3 & 1,3 \\
\hline 2 & Pal & 3,2 & 3,2 \\
\hline 3 & PalPr & 1,3 & - \\
\hline 4 & PalSil, SilPal & 3,2 & 2,6 \\
\hline 5 & PrPal & 4,5 & 5,1 \\
\hline 6 & Pr & 2,6 & 1,3 \\
\hline 7 & PrPs & 1,3 & 1,3 \\
\hline 8 & PrRu & 1,9 & - \\
\hline 9 & PrSil & 1,9 & - \\
\hline 10 & Ps, PsRu & 1,3 & 1,3 \\
\hline 11 & PsSil, SilPs & 1,3 & - \\
\hline 12 & PsSt, StPs & 1,3 & 2,6 \\
\hline 13 & Ru & 11,5 & 12,8 \\
\hline 14 & RuSt & 1,9 & - \\
\hline 15 & RuPr & 1,9 & 2,6 \\
\hline 16 & RuSil & 5,8 & 5,1 \\
\hline 17 & Sil & 26,9 & 40,4 \\
\hline 18 & SilPr & 6,4 & 3,2 \\
\hline 19 & SilRu & 3,8 & 1,3 \\
\hline 20 & SilSt & 5,1 & 7,7 \\
\hline 21 & St & 1,3 & - \\
\hline 22 & PrSt, StPr & 5,1 & 4,5 \\
\hline 23 & StRu & 2,6 & 1,9 \\
\hline 24 & StSil & 2,6 & 1,9 \\
\hline
\end{tabular}

Таблииа 3

Центроиды групп видов степных лиственных лесов

\begin{tabular}{|l|c|c|c|c|c|c|c|c|c|c|}
\hline \multirow{2}{*}{ Ценоморфа } & \multicolumn{10}{|c|}{ Центроиды групп, балл } \\
\cline { 2 - 12 } & Tm & Kn & Om & Cr & Hd & Tr & Rc & Nt & Lc & Hm \\
\hline HalPr, PrHal & 7,2 & 9,0 & 7,3 & 6,1 & 13,3 & 7,0 & 7,3 & 7,2 & 1,9 & 3,5 \\
\hline Pal & 8,5 & 8,5 & 7,8 & 8,1 & 15,5 & 7,3 & 7,3 & 7,0 & 3,5 & 3,9 \\
\hline SilPal & 9,0 & 8,5 & 8,0 & 8,2 & 15,2 & 6,0 & 6,7 & 5,5 & 3,7 & 3,2 \\
\hline PrPal & 8,9 & 8,7 & 8,2 & 7,7 & 13,9 & 8,6 & 8,2 & 6,4 & 3,2 & 3,7 \\
\hline Pr & 7,5 & 8,8 & 8,0 & 6,4 & 12,5 & 8,3 & 7,1 & 6,1 & 3,1 & 3,8 \\
\hline PrPs & 8,4 & 8,6 & 7,6 & 7,6 & 11,9 & 8,1 & 6,6 & 6,5 & 3,2 & 2,9 \\
\hline Ps & 9,6 & 9,4 & 7,1 & 8,1 & 9,9 & 7,1 & 6,2 & 5,8 & 2,6 & 2,3 \\
\hline PsSt, StPs & 8,1 & 8,9 & 7,8 & 7,4 & 9,3 & 8,0 & 8,1 & 4,6 & 3,2 & 2,3 \\
\hline Ru & 8,4 & 8,2 & 7,5 & 7,8 & 10,7 & 7,3 & 6,9 & 6,6 & 2,8 & 2,9 \\
\hline RuPr & 8,2 & 8,6 & 7,6 & 7,5 & 12,4 & 8,9 & 7,0 & 6,4 & 2,9 & 2,6 \\
\hline RuSil & 8,1 & 8,5 & 7,8 & 7,9 & 12,2 & 6,6 & 7,1 & 7,8 & 4,0 & 3,5 \\
\hline Sil & 8,7 & 8,4 & 7,9 & 8,2 & 12,4 & 6,8 & 7,6 & 6,4 & 4,4 & 3,2 \\
\hline SilPr & 8,4 & 8,5 & 7,7 & 7,7 & 11,2 & 6,4 & 7,2 & 5,2 & 3,5 & 3,1 \\
\hline SilRu & 8,3 & 8,6 & 7,8 & 7,6 & 13,0 & 7,5 & 8,0 & 7,9 & 3,9 & 3,7 \\
\hline SilSt & 9,2 & 8,9 & 7,4 & 8,4 & 10,8 & 7,1 & 8,0 & 6,0 & 3,5 & 3,2 \\
\hline PrSt, StPr & 8,7 & 9,1 & 7,4 & 7,9 & 10,3 & 7,1 & 7,6 & 5,3 & 3,3 & 3,0 \\
\hline StRu & 8,8 & 7,9 & 8,0 & 8,7 & 8,5 & 7,6 & 7,8 & 7,9 & 2,7 & 2,9 \\
\hline StSil & 8,7 & 8,1 & 7,9 & 8,4 & 12,2 & 7,8 & 8,3 & 4,9 & 4,2 & 3,7 \\
\hline
\end{tabular}


3. Индикаторами солевого режима являются лесо-болотная (наименьшие показатели, гликопермезофитная свита) и сорно-луговая (наибольшие показатели, гликоэвтрофная свита) ценоморфы.

4. Наиболее специфическими экологическими факторами идентифицируются ценоморфы: псаммофитная (максимальные значения терморежима и континентальности при минимальных показателях омброрежима, кислотности почв и содержания гумуса); степных рудерантов (максимальные значения криорежима и режима гумуса при минимальных показателях континентальности и почвенного увлажнения). Первая группа связана с наиболее засушливыми бедными псаммофитными степями арен, характеризующимися наиболее высокими температурами и значительными их колебаниями, а вторая - сухими нарушенными степными сообществами.

5. Индикаторами богатых азотом почв (нитрофильных вариантов трофотопов) являются ценоморфы лесных рудерантов. При этом сорно-лесная характерна для мезофильных, а лесо-сорная - мезогигрофильных гигротопов.

6. Индикаторами кислотности почв (максимальные значения в кальцефильных вариантах трофотопов) являются ценоморфы лугово-болотная (характерна для гигрофильных) и степо-лесная (для мезофильных гигротопов).

7. Лесная ценоморфа характеризуется максимальными показателями режима освещенности и является индикатором наиболее теневых условий.

Таким образом, ценоморфы четко разграничиваются в пространстве абиотических факторов, которое соответствует аутэкологическим особенностям видов, входящих в конкретные ценоморфы, следовательно, последние могут служить не только индикаторами ценотических характеристик лесных сообществ, но и климатопов, трофотопов и гигротопов лиственных лесов.

Дискриминантный анализ в эколого-ценотическом пространстве показал наличие в модели 10 переменных из 13 (исключались омбро- и криорежим и вторая ось NMS). Ведущими факторами дискриминации переменных были (по уменьшению): почвенное увлажнение, освещенность, азотный режим и ценотические переменные (первая и третья оси NMS). Результаты дискриминации в целом были статистически значимыми ( $F$-критерий превышает предельное значение).

Ординация ценоморф в пространстве абиотических факторов выполнена методом корреляционных плеяд [10] по матрице квадрата расстояния Махаланобиса (рис. 1). Наиболее экологически близкими в пространстве абиотических факторов оказались ценоморфы лугово-псаммофитная и рудеральная, характерные для антропогенных и антропогенно трансформированных колков. Наименее близкими (квадрат расстояния Махаланобиса - 192,2) были ценоморфы лесо-болотная и степных рудерантов.

Для дендрограммы характерна структура типа «звезда» с двумя экотопическими центрами: мезоксерофильным лугово-псаммофильно - рудеральным и мезофильным лесным и сорно-лесным. Оба центра связаны переходной лесо-луговой ценоморфой, центром ряда ценоморф экотонов полянных комплексов плакорных дубрав и экотонов колковых лесов, переходных к псаммофильным степям арен. Также по два экотопических ряда замещения характерны для обоих центров.

Таким образом, для ценоморф исследованных лесов формируются четкая сильвантная группа видов, для которой характерны нитрофильный, кальцефильный и рудеральный ряды экотопического замещения. Помимо этого формируются ряды замещения амфиценотических лесных сообществ (колков и ольшаников) - псаммофильных, луговых и болотных. Расположение ценоморф в пространстве абиотических факторов отвечает ординации лесных экосистем степных ландшафтных комплексов. 


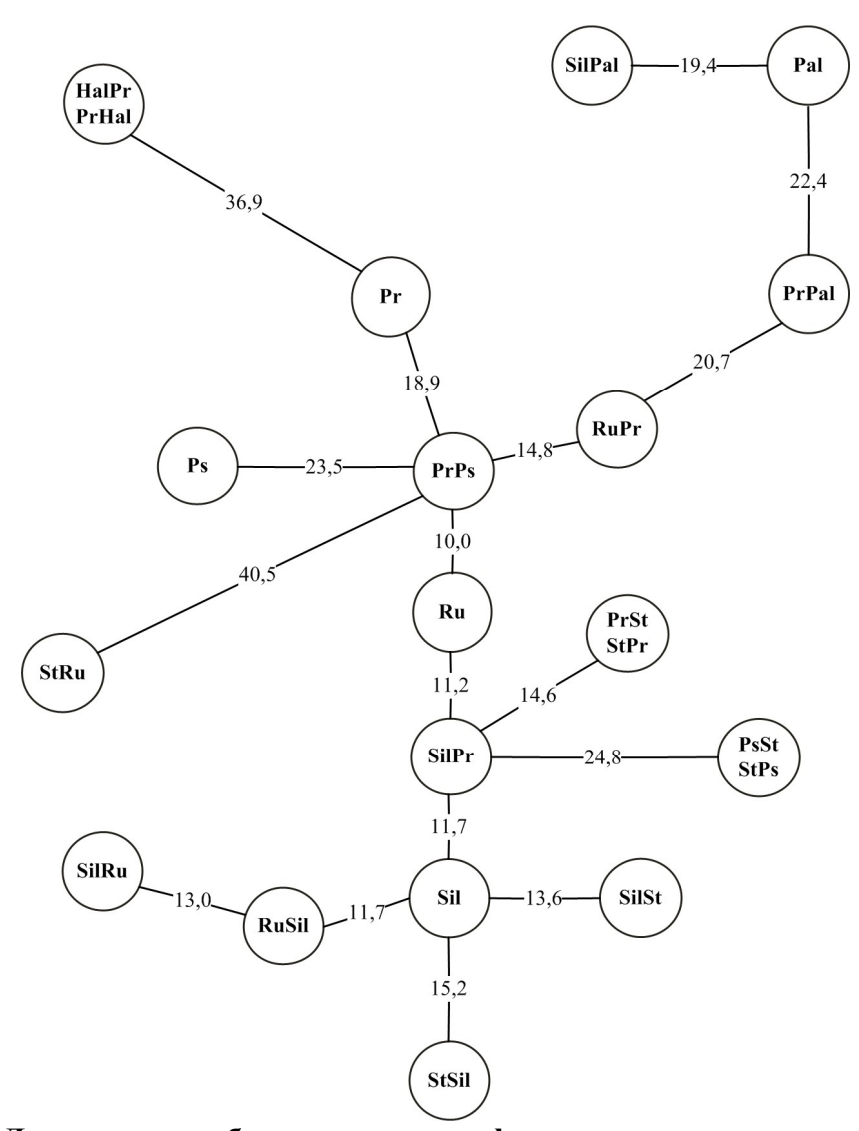

Рис. 1. Дендрограмма близости ценоморф в экологическом пространстве

Дискриминантный анализ с редуцированной переменной (табл. 4) показывает, что точность выделения конкретных ценоморф зависит от наличия или отсутствия определенной переменной. Таким образом, выделяются критические факторы, которые определяют включение вида в ту или иную ценоморфу.

Определены следующие критические факторы: 1) освещенность (для лесостепной ценоморфы), 2) почвенное увлажнение (лесная и лугово-болотная), 3) режим гумуса (степо-лесная), 4) ценотические характеристики (оси NMS) - лугово-степная, 5) азотный режим (сорно-лесная); 6) ценотические характеристики и почвенное увлажнение - лесо-болотная; 7) ценотические характеристики, почвенное увлажнение и режим гумуса - лугово-псаммофитная; 8) ценотические характеристики, почвенное увлажнение и освещенность - лесо-луговая. Устойчивыми (редукция переменной не оказала влияния на ценоморфу) оказались лугово-галофитная, лесо-рудеральная, степорудеральная, луговая и псаммофитная ценоморфы. Для остальных ценоморф на их формирование оказывает влияние комплекс из четырех - десяти факторов, что указывает на существенные аутэкологические особенности видов, их слагающих. В подавляющем большинстве случаев определяющим для включения видов в ценоморфу являлся режим почвенного увлажнения. Критическими факторами размежевания видов на ценоморфы являются:

1) почвенное увлажнение - для пар лесо-рудеральная - болотная, лесо-болотная - лесо-луговая, лугово-болотная - луговая, рудеральная - лугово-псаммофитная, лесо-луговая - лесо-болотная, степо-рудеральная - рудеральная; 
2) режим гумуса - для пар луговая - сорно-луговая, лесная - степо-лесная;

3) азотный режим - для пар рудеральная - лесо-луговая, лесная - сорно-лесная, степо-лесная - лесная;

4) терморежим - псаммофиты - рудеральная;

5) ценотические характеристики (оси NMS) - для пар луговые галофиты - луговые, луговые псаммофиты - сорно-луговые, степные псаммофиты - лугово-степные, рудеранты - луговые псаммофиты; сорно-лесные - луговые псаммофиты, сорнолесные - лесные рудеранты, лесные - лесо-луговые, лесо-луговые - лесо-степные, лесо-луговые - лугово-степные, лесо-степные - лугово-степные.

Доля (\%) правильно классифицированных на ценоморфы видов

Таблий 4 в дискриминантном анализе с редуцированной переменной

\begin{tabular}{|l|c|c|c|c|c|c|c|c|c|c|c|}
\hline \multirow{2}{*}{ Ценоморфа } & \multicolumn{10}{|c|}{ Редуцированная переменная } \\
\cline { 2 - 13 } & $\mathrm{NMS}$ & $\mathrm{Tm}$ & $\mathrm{Kn}$ & $\mathrm{Om}$ & $\mathrm{Cr}$ & $\mathrm{Hd}$ & $\mathrm{Tr}$ & $\mathrm{Rc}$ & $\mathrm{Nt}$ & $\mathrm{Lc}$ & $\mathrm{Hm}$ \\
\hline HalPr, PrHal & 100,0 & 100,0 & 100,0 & 100,0 & 100,0 & 100,0 & 100,0 & 100,0 & 100,0 & 100,0 & 100,0 \\
\hline Pal & 100,0 & 80,0 & 100,0 & 100,0 & 100,0 & 80,0 & 80,0 & 100,0 & 100,0 & 100,0 & 80,0 \\
\hline SilPal & 50,0 & 75,0 & 100,0 & 100,0 & 100,0 & 50,0 & 75,0 & 100,0 & 75,0 & 100,0 & 100,0 \\
\hline PrPal & 87,5 & 87,5 & 87,5 & 87,5 & 87,5 & 75,0 & 87,5 & 87,5 & 87,5 & 100,0 & 100,0 \\
\hline Pr & 100,0 & 100,0 & 100,0 & 100,0 & 100,0 & 100,0 & 100,0 & 100,0 & 100,0 & 100,0 & 100,0 \\
\hline PrPs & 50,0 & 100,0 & 100,0 & 100,0 & 100,0 & 50,0 & 100,0 & 100,0 & 100,0 & 100,0 & 50,0 \\
\hline Ps, PsRu & 100,0 & 100,0 & 100,0 & 100,0 & 100,0 & 100,0 & 100,0 & 100,0 & 100,0 & 100,0 & 100,0 \\
\hline PsSt, StPs & 75,0 & 75,0 & 100,0 & 75,0 & 75,0 & 75,0 & 100,0 & 75,0 & 75,0 & 100,0 & 100,0 \\
\hline Ru & 85,0 & 80,0 & 85,0 & 80,0 & 80,0 & 80,0 & 80,0 & 85,0 & 80,0 & 80,0 & 80,0 \\
\hline RuPr & 75,0 & 75,0 & 100,0 & 75,0 & 75,0 & 75,0 & 75,0 & 75,0 & 75,0 & 75,0 & 75,0 \\
\hline RuSil & 100,0 & 50,0 & 87,5 & 75,0 & 75,0 & 75,0 & 75,0 & 75,0 & 50,0 & 87,5 & 87,5 \\
\hline Sil & 100,0 & 95,2 & 96,8 & 98,4 & 98,4 & 92,1 & 98,4 & 98,4 & 96,8 & 96,8 & 95,2 \\
\hline SilPr & 40,0 & 60,0 & 60,0 & 60,0 & 60,0 & 40,0 & 60,0 & 60,0 & 60,0 & 40,0 & 60,0 \\
\hline SilRu & 100,0 & 100,0 & 100,0 & 100,0 & 100,0 & 100,0 & 100,0 & 100,0 & 100,0 & 100,0 & 100,0 \\
\hline SilSt & 83,3 & 91,7 & 83,3 & 91,7 & 91,7 & 91,7 & 91,7 & 91,7 & 100,0 & 75,0 & 91,7 \\
\hline PrSt, StPr & 28,6 & 71,4 & 85,7 & 71,4 & 71,4 & 57,1 & 85,7 & 71,4 & 71,4 & 71,4 & 71,4 \\
\hline StRu & 100,0 & 100,0 & 100,0 & 100,0 & 100,0 & 100,0 & 100,0 & 100,0 & 100,0 & 100,0 & 100,0 \\
\hline StSil & 100,0 & 100,0 & 100,0 & 100,0 & 100,0 & 100,0 & 100,0 & 100,0 & 100,0 & 100,0 & 66,7 \\
\hline
\end{tabular}

Для большинства ценоморф статистически подтверждается именно ценотическая их обособленность, то есть ценоморфы статистически достоверно определяют ценотическую приуроченность видов. Однако для части ценоморф характерно обособление видов преимущественно в связи с условиями гигротопа и трофотопа. Ценоморфы, кроме индикаторов ценотических характеристик сообщества, могут использоваться в качестве индикаторов почвенного увлажнения, азотного режима и режима гумуса.

Ординация в пространстве осей NMS демонстрирует наличие двух практически не связанных ценотических рядов (рис. 2), которые наиболее выражены по первой и третьей осям NMS. Один ряд определяется как сильвантный, начинается лесо-степными и степо-лесными ценоморфами видов опушечных комплексов и, через лесную и сорнолесную группы идет к болотной группе и лесным рудерантам. Данный ряд отображает характер смены лесных ценозов от опушек байраков и пристенов к тальвегам и руслам рек, а также прирусловья - центральной поймы - притеррасья краткопоемных дубрав и ольшаников. Второй - амфиценотический «нелесной» - состоит из двух параллельных рядов ценоморф полянного комплекса, переходных к сильвантному ряду, и ценоморф аренного комплекса. Оба эти ряда характерны для экотонов лесных экосистем с болотными, лесными, луговыми, степными и псаммофильными экосистемами. 

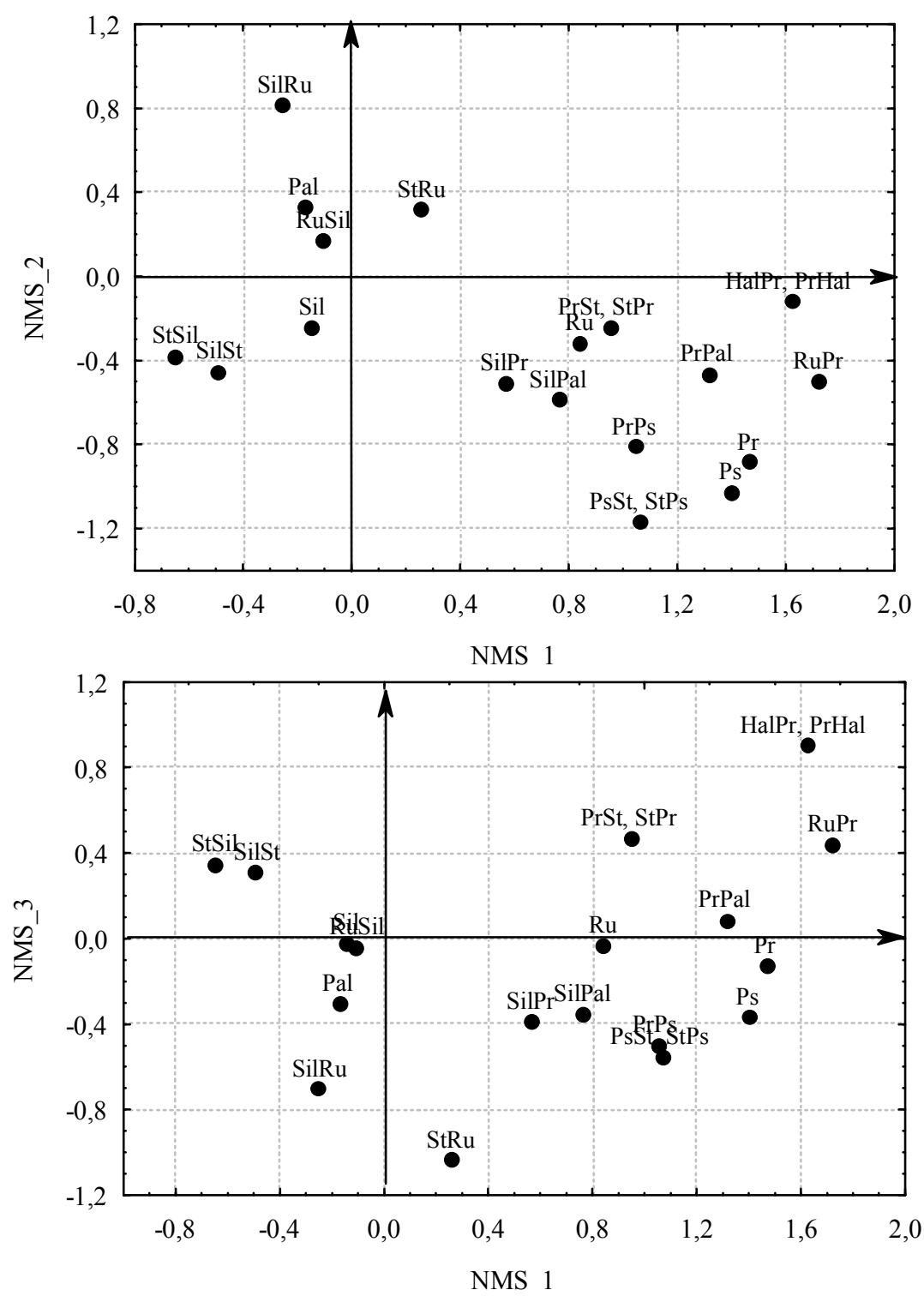

Рис. 2. Ординация ценоморф в ценотическом пространстве:

NMS_1, NMS_2, NMS_3 - ординационные оси неметрического многомерного шкалирования

Ординация центроидов ценоморф в эколого-ценотическом пространстве (рис. 3) подтверждает наличие двух рядов эколого-ценотического замещения (сильвантного и амфиценотического), которые отображают характер смены растительных комплексов лиственных лесов в Степи - 1) дубравного байрачно-пристенно-краткопоемного, 2) аренного, преимущественно лугово-псаммофильного и 3) краткопоемного дубравноольшаникового, преимущественно болотного и лесо-болотного.

В результате экспертно-статистического анализа для части видов степных лиственных лесов ценоморфа была уточнена (табл. 5) - номенклатура видов подана по В. В. Тарасову [9]. Выделяются 22 «переходных» вида, для которых определены близкие апостериорные вероятности отнесения одновременно к двум и более ценоморфам, что подтверждает некоторую условность ценоморфической классификации видов. 


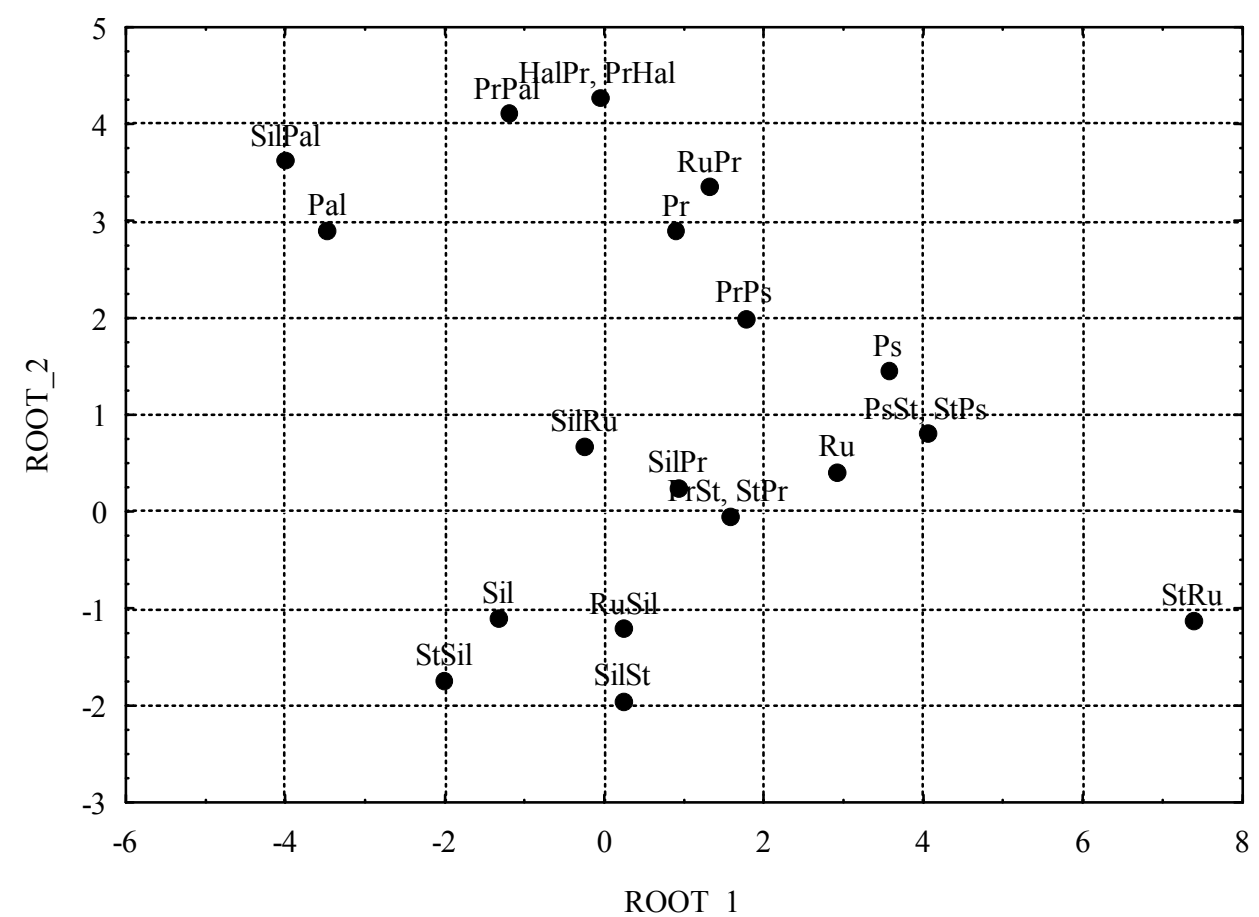

Рис. 3. Ординация ценоморф в эколого-ценотическом пространстве:

ROOT_1, ROOT_2-оси первых дискриминантных функций

Таблииа 5

Виды лиственных северо-степных лесов, для которых ценоморфа была уточнена

\begin{tabular}{|c|c|c|c|}
\hline Вид & $\begin{array}{l}\text { Экспертная } \\
\text { ценоморфа }\end{array}$ & $\begin{array}{c}\text { Расчетная } \\
\text { ценоморфа }\end{array}$ & Близкая ценоморфа \\
\hline 1 & 2 & 3 & 4 \\
\hline Aconitum nemorosum M.Bieb. ex Rchb. & $\operatorname{PrSil}(0,03)$ & Sil $(0,69)$ & - \\
\hline Adonis vernalis $\mathrm{L}$. & St $(0,09)$ & Sil $(0,40)$ & StSil $(0,17) ; \operatorname{SilSt}(0,14)$ \\
\hline Agrimonia eupatoria L. & SilSt $(0,03)$ & Sil $(0,67)$ & $\operatorname{SilPr}(0,10)$ \\
\hline Agrostis gigantea Roth. & $\operatorname{SilPr}(0,07)$ & SilRu $(0,30)$ & $\operatorname{RuSil}(0,26) ; \operatorname{Sil}(0,10)$ \\
\hline Alliaria petiolata (Bieb.) Cav. et Grande & $\operatorname{RuSt}(0,03)$ & Sil $(0,47)$ & $\operatorname{RuSil}(0,27) ; \operatorname{SilRu}(0,11)$ \\
\hline Alnus glutinosa (L.) Gaertn. & Sil $(0,03)$ & $\operatorname{Pal}(0,44)$ & PalSil, SilPal $(0,37) ; \operatorname{PrPal}(0,11)$ \\
\hline Alsine media $\mathrm{L}$. & $\mathrm{Ru}(0,24)$ & Sil $(0,25)$ & RuSil $(0,18) ; \operatorname{SilRu}(0,13) ; \operatorname{SilPr}(0,10)$ \\
\hline Arctium lappa $\mathrm{L}$. & $\mathrm{Ru}(0,04)$ & Sil $(0,49)$ & $\operatorname{RuSil}(0,23) ; \operatorname{SilRu}(0,12)$ \\
\hline Aristolochia clematitis L. & $\operatorname{RuSil}(0,14)$ & SilSt $(0,21)$ & $\operatorname{SilRu}(0,19) ; \mathrm{Ru}(0,15)$ \\
\hline Artemisia vulgaris $\mathrm{L}$. & $\operatorname{PrRu}(0,09)$ & $\mathrm{Ru}(0,77)$ & - \\
\hline Bidens tripartita $\mathrm{L}$. & $\operatorname{PalPr}(0,15)$ & $\operatorname{PrPal}(0,43)$ & $\operatorname{Pal}(0,40)$ \\
\hline Campanula trachelium $\mathrm{L}$. & PrSil $(0,08)$ & Sil $(0,81)$ & - \\
\hline Carex michelii Host. & PalStPr $(0,00)$ & Sil $(0,69)$ & $\operatorname{SilPr}(0,09)$ \\
\hline C. riparia Curt. & $\operatorname{Pal}(0,38)$ & $\operatorname{PrPal}(0,45)$ & $\operatorname{PalPr}(0,10)$ \\
\hline C. spicata Huds. & PsSil $(0,17)$ & Sil $(0,50)$ & $\operatorname{PrPal}(0,11)$ \\
\hline Chenopodium hybridum $\mathrm{L}$. & $\mathrm{Ru}(0,03)$ & Sil $(0,26)$ & RuSil $(0,23) ; \operatorname{RuSt}(0,18) ; \operatorname{SilRu}(0,16)$ \\
\hline Crataegus leiomonogyna Klokov & StSil $(0,12)$ & Sil $(0,31)$ & $\operatorname{SilSt}(0,28) ; \operatorname{SilPr}(0,10)$ \\
\hline Cynoglossum officinale L. & $\mathrm{Ru}(\mathrm{St})(0,27)$ & $\operatorname{RuSil}(0,32)$ & SilRu $(0,24)$ \\
\hline Dactylis glomerata L. & $\operatorname{SilPr}(0,12)$ & Sil $(0,33)$ & $\operatorname{RuSil}(0,19) ; \operatorname{Ru}(0,14) ; \operatorname{SilRu}(0,11)$ \\
\hline Daucus carota $\mathrm{L}$. & $\operatorname{PrRu}(0,17)$ & $\operatorname{StPr}(0,37)$ & $\mathrm{Ru}(0,33)$ \\
\hline Elytrigia repens (L.) Nevski & $\operatorname{StPrRu}(0,04)$ & $\operatorname{RuPr}(0,64)$ & $\operatorname{Pr}(0,19)$ \\
\hline Erodium cicutarium (L.) L'Her. & $\operatorname{StRu}(0,01)$ & $\mathrm{Ru}(0,47)$ & $\operatorname{PrRu}(0,16) ; \operatorname{SilPr}(0,12)$ \\
\hline Erysimum repandum L. & $\mathrm{Ru}(0,04)$ & SilSt $(0,73)$ & St $(0,10)$ \\
\hline Fallopia convolvulus (L.) Love & $\operatorname{SilRu}(0,13)$ & $\operatorname{SilPr}(0,24)$ & Sil $(0,23) ; \operatorname{Ru}(0,19)$ \\
\hline Filipendula denudata (J. et C.Presl) Fitsch & SilPal $(0,13)$ & Sil $(0,26)$ & $\operatorname{Pal}(0,16) ; \operatorname{PsSil}, \operatorname{SilPs}(0,15) ; \operatorname{PalPr}(0,10)$ \\
\hline
\end{tabular}




\begin{tabular}{|c|c|c|c|}
\hline & & & Окончание табл. 5 \\
\hline 1 & 2 & 3 & 4 \\
\hline Fragaria viridis (Duchesne) Weston & $\operatorname{SilPr}(0,13)$ & Sil $(0,53)$ & SilSt $(0,11)$ \\
\hline Galium aparine L. & SilRu $(0,18)$ & $\mathrm{Ru}(0,45)$ & $\operatorname{RuSil}(0,20)$ \\
\hline G. mollugo L. & $\operatorname{SilPr}(0,06)$ & Sil $(0,79)$ & $\operatorname{PrSil}(0,12)$ \\
\hline G. rubioides L. & $\operatorname{Pr}(0,05)$ & Sil $(0,60)$ & - \\
\hline Geum urbanum L. & $\operatorname{RuSil}(0,16)$ & Sil $(0,69)$ & - \\
\hline Glechoma hederacea L. & $\operatorname{RuSil}(0,32)$ & Sil $(0,43)$ & SilRu $(0,13)$ \\
\hline Heracleum sibiricum L. & PrSil $(0,31)$ & Sil $(0,54)$ & - \\
\hline Hylotelephium maximum (L.) Holub & Sil $(0,12)$ & SilSt $(0,69)$ & - \\
\hline H. polonicum (Bloki) Holub. & $(\operatorname{Sil}) \operatorname{StPr}(0,02)$ & Sil $(0,43)$ & $\operatorname{SilPr}(0,20) ; \operatorname{SilSt}(0,15)$ \\
\hline Hypericum perforatum L. & SilPr $(0,04)$ & SilSt $(0,41)$ & Sil $(0,33)$ \\
\hline Impatiens noli-tangere $\mathrm{L}$ & PalSil $(0,00)$ & Sil $(0,92)$ & - \\
\hline Lamium album $\mathrm{L}$. & SilRu $(0,13)$ & $\operatorname{RuSil}(0,31)$ & RuSt $(0,17) ; \operatorname{Sil}(0,13)$ \\
\hline L. maculatum (L.)L. & SilRu $(0,10)$ & Sil $(0,62)$ & $\operatorname{RuSil}(0,16)$ \\
\hline L. purpureum L. & SilRu $(0,13)$ & SilPr $(0,37)$ & Sil $(0,15)$ \\
\hline Lathyrus megalanthus Steud. & Sil $(0,07)$ & $\mathrm{Ru}(0,57)$ & $\operatorname{SilPr}(0,13) ; \operatorname{StRu}(0,10)$ \\
\hline Linaria vulgaris Mill. & $\operatorname{PrRu}(0,12)$ & PsSt $(0,86)$ & - \\
\hline Melandrium album (Mill.) Garcke & $\operatorname{SilPr}(0,05)$ & $\mathrm{Ru}(0,53)$ & - \\
\hline Melica picta C. Koch & Sil $(0,12)$ & StSil $(0,43)$ & SilSt $(0,23) ;$ PsSil, SilPs $(0,10) ; \operatorname{St}(0,10)$ \\
\hline Mentha verticillata $\mathrm{L}$. & $\operatorname{Pr}(0,32)$ & $\mathrm{Ru}(0,34)$ & $\operatorname{PrRu}(0,22)$ \\
\hline Peucedanum oreoselinum (L.) Moench. & SilPs $(0,09)$ & Sil $(0,57)$ & $\operatorname{SilPr}(0,15) ; \operatorname{SilSt}(0,10)$ \\
\hline Phlomis tuberosa L. & St $(0,13)$ & SilSt $(0,30)$ & $\operatorname{SilPr}(0,10) ; \operatorname{SilRu}(0,10)$ \\
\hline Phragmites australis (Cav.) Trin. ex Steud. & $\operatorname{Pal}(0,37)$ & $\operatorname{PrPal}(0,46)$ & PalSil, SilPal $(0,10)$ \\
\hline Pinus sylvestris L. & Sil $(0,30)$ & SilPal $(0,53)$ & - \\
\hline Poa bulbosa L. & $\operatorname{RuSt}(0,04)$ & SilSt $(0,60)$ & - \\
\hline P. palustris L. & $\operatorname{PrPal}(0,02)$ & $\operatorname{SilRu}(0,38)$ & $\operatorname{RuSil}(0,37) ; \operatorname{Sil}(0,12)$ \\
\hline Polygonum aviculare L. s. str. & $\mathrm{Ru}(0,02)$ & Sil $(0,59)$ & SilRu $(0,11) ; \operatorname{SilPr}(0,10)$ \\
\hline Ranunculus acris $\mathrm{L}$. & $\operatorname{Pr}(0,04)$ & $\operatorname{RuPr}(0,58)$ & $\operatorname{PrPs}(0,21)$ \\
\hline Rosa canina $\mathrm{L}$ & SilSt $(0,28)$ & Sil $(0,52)$ & - \\
\hline Scirpus lacustris L. & Pal $(0,38)$ & $\operatorname{PrPal}(0,48)$ & PalPr $(0,14)$ \\
\hline Setaria viridis (L.) Beauv. & PsRu $(0,01)$ & Ps $(0,98)$ & - \\
\hline Stachys palustris L. & $\operatorname{PrPal}(0,06)$ & $\operatorname{Pal}(0,68)$ & $\operatorname{PalPr}(0,24)$ \\
\hline Stellaria graminea $\mathrm{L}$. & $\operatorname{SilPr}(0,05)$ & PsSt $(0,84)$ & - \\
\hline Tanacetum vulgare $\mathrm{L}$. & $\operatorname{StPr}(0,20)$ & $\operatorname{Pr}(0,39)$ & $\operatorname{PalPr}(0,21) ; \operatorname{PrPal}(0,11)$ \\
\hline Taraxacum officinale Webb. ex Wigg. & $\operatorname{RuPr}(0,04)$ & $\mathrm{Ru}(0,76)$ & - \\
\hline Torilis japonica $($ Houtt.) DC. & RuSil $(0,02)$ & Sil $(0,43)$ & StSil $(0,34)$ \\
\hline Urtica dioica $\mathrm{L}$ & SilRu $(0,23)$ & $\operatorname{RuSil}(0,50)$ & Sil $(0,19)$ \\
\hline Vincetoxicum hirundinaria Medik. & StSil $(0,07)$ & SilSt $(0,79)$ & \\
\hline Viola montana s. str. & SilSt $(0,12)$ & Sil $(0,55)$ & StSil $(0,10)$ \\
\hline V. suavis Bieb. & Sil $(0,13)$ & $\operatorname{StPr}(0,43)$ & $\operatorname{SilPr}(0,21) ; \operatorname{SilRu}(0,10)$ \\
\hline
\end{tabular}

Примечание: в скобках возле ценоморфы - апостериорная вероятность.

\section{Выводы}

1. Экспертно-статистическая оценка системы ценоморф не противоречит фундаментальным данным аутэкологии видов сосудистых растений и экологическим особенностям естественных северо-степных лиственных лесов и может использоваться при оценке ценоморф в Степной зоне Украины.

2. Ценоморфы северо-степных лесов формируют ряды эколого-ценотического замещения, отвечающие ординации лесных экосистем ландшафтных комплексов Степи Украины. Для подавляющего большинства ценоморф статистически подтверждается ценотическая их обособленность, таким образом, ценоморфы статистически достоверно определяют ценотическую приуроченность видов. Помимо ценоморфического анализа, ценоморфы могут использоваться в качестве фитоиндикаторов условий увлажнения, почвенных солевого, азотного, кислотного режимов и содержания гумуса. 
Для северо-степных лиственных лесов рекомендуется использовать уточненную систему ценоморф.

3. Ценоморфы характеризуются достаточно высокой вариабельностью, а переход вида в ту или иную ценоморфу зависит от типа анализируемого растительного сообщества. В подавляющем большинстве случаев определяющим для включения видов в ценоморфу являлся режим почвенного увлажнения. Выделение переходных ценоморф не всегда бывает целесообразным, особенно для амфиценотических сообществ, в связи с наличием «промежуточных» видов.

4. В дальнейшем необходима проверка экспертно-статистическими методами системы ценоморф северо-степных лесов на примере искусственных лиственных лесов и хвойных естественных и искусственных лесов.

\section{Библиографические ссылки}

1. Бельгард А. Л. Об амфиценозах // Научн. зап. Днепропетр. гос. ун-та. - Д. : ДГУ, 1948. C. 87-89.

2. Бельгард А. Л. Лесная растительность юго-востока УССР. - К. : КГУ, 1950. - 263 с.

3. Бондар Г. С. Екологічний аналіз трав'янистої рослинності схилових екотопів ПівденноСхідного Степу України (відновлення, охорона, раціональне використання): Автореф. дис. ... канд. біол. наук: 03.00.16 - Екологія. - Д. : ДНУ, 2001. - 19 с.

4. Восточноевропейские леса: История в голоцене и современность / Под ред. О. В. Смирновой. - М. : Наука, 2004. - Т. 1. - 479 с.

5. Дідух Я. П. Фітоіндикація екологічних факторів / Я. П. Дідух, П. Г. Плюта. - К. : Наук. думка, 1994. $-280 \mathrm{c}$.

6. Матвеев Н. М. Биоэкологический анализ флоры и растительности (на примере лесостепной и степной зоны). - Самара : Самарск. ун-т, 2006. - 311 с.

7. Назаренко Н. М. Ценоморфи інтразональних лісових екосистем терас малих річок Північного Степу України / Н. М. Назаренко, І. М. Лоза // Агроеколог. журн. - 2010. - № 4. - С. 24-30.

8. Смирнов В. Э. Обоснование системы эколого-ценотических групп видов растений лесной зоны Европейской России на основе экологических шкал, геоботанических описаний и статистического анализа / В. Э. Смирнов, Л. Г. Ханина, М. В. Бобровский // Бюлл. МОИП. Отд. биол. $-2006 .-$ Т. 111, вып. 2. - С. 36- 47.

9. Тарасов В. В. Флора Дніпропетровської та Запорізької областей. Судинні рослини. Біологоекологічна характеристика видів. - Д. : Вид-во ДНУ, 2005. - 276 с.

10. Терентьев П. В. Метод корреляционных плеяд // Вестн. Ленинград. гос. ун-та. - 1959. № 9. - С. 137-141.

11. Цыганов Д. Н. Фитоиндикация экологических факторов в подзоне хвойно-широколиственных лесов. - М. : Наука, 1983. - 198 с.

12. Legendre L. Numerical Ecology / L. Legendre, P. Legendre. - Amsterdam : Elsevier Science B. V., 1998. $-853 \mathrm{p}$.

13. McCune B. Analysis of Ecological Communities / B. McCune, J. B. Grace. - MjM SoftWare Design, 2002. $-300 \mathrm{p}$.

Надійшла до редколегії 05.02.2012 